\title{
Biochar from Empty Fruit Bunches, Wood, and Rice Husks: Effects on Soil Physical Properties and Growth of Sweet Corn on Acidic Soil
}

\author{
Huda Abdulrazzaq ${ }^{1}$, Hamdan Jol ${ }^{1}$, Ahmed Husni ${ }^{1} \&$ Rosenani Abu-Bakr ${ }^{1}$ \\ ${ }^{1}$ Department of Land Management, Faculty of Agriculture, Universiti Putra Malaysia, Selangor, Malaysia \\ Correspondence: Huda Abdulrazzaq, Department of Land Management, Faculty of Agriculture, Universiti Putra \\ Malaysia, 43400 UPM Serdang, Selangor, Malaysia. E-mail: hudaalgailani@yahoo.com
}

\author{
Received: October 17, 2014 Accepted: November 17, 2014 Online Published: December 15, 2014 \\ doi:10.5539/jas.v7n1p192 URL: http://dx.doi.org/10.5539/jas.v7n1p192
}

\begin{abstract}
The Intentional amendment of soil with biochar is offering a new strategy for enhancing soil physical properties and soil fertility. Nonetheless, the characteristics of biochars vary with their different conditions and pyrolysis techniques. The objective of the present study was to improve the understanding of how adding biochar applications and the pyrolysis of native feedstock to acidic soil can be utilized to amend soil physical properties and soil fertility in Malaysia. Three kinds of primary biochar were used, empty fruit bunch (EFB) and wood biochar (WB) were produced from slow pyrolysis, and rice husk biochar (RHB) was prepared by gasification. The biochars were characterized by Brunauer-Emmett-Teller surface area analysis and scanning electron microscopy and applied at 15 and $30 \mathrm{t} / \mathrm{ha}$ to acidic soil. Results indicated that the total surface area of the RHB was approximately double of that of EFB and five times greater than that of WB. The application of RHB at 30 t/ha significantly increased the drained upper limit, permanent wilting point, hydraulic conductivity, and total porosity; however, this increase did not result in increased sweet corn growth, while EFB applied at rates $30 \mathrm{t} / \mathrm{ha}$ resulted in a highly positive effect on sweet corn growth, suggesting that EFB has important potential benefits for agriculture, in conclusion, the selection of biochar as a soil amendment must be based on the intention of the amendment. If to enhance soil physical charactertics are an aim, then RHB is the most suitable option. If the objective of soil biochar amendment is to increase soil fertility, then EFB will be suitable choice.
\end{abstract}

Keywords: biochar, slow pyrolysis, gasification, soil physical properties, sweet corn growth

\section{Introduction}

The highly porous biochar is believed to improve the physical properties of soil, such as bulk density, total porosity, pore-size distribution, soil moisture content, water holding capacity, and hydraulic conductivity (Ahmad et al., 2014; Belyaeva \& Haynes, 2012; Brewer et al., 2012; Chan et al., 2007, 2010; Ventura et al., 2012).

Positive and negative agronomic effects were noticed after biochar amendment (Guerena et al., 2013; Major et al., 2010; Gaskin et al., 2010). Therefore, the application of biochar to soil does not follow a "one-size-fits-all" paradigm. Half of the reviewed studies in literature have reported an increase in plant growth and crop yields after biochar application because biochar improves soil fertility, reduces the bioaccumulation of toxic metals, and mitigates climate change (Jaiswal et al., 2014; Masto et al., 2013; Tian et al., 2012). However, 30\% of the studies found no significant benefits (Devereux et al., 2012), and the remainder suggested negative effects (Gajic \& Koch, 2012; Kloss et al., 2014). The unfavorably high $\mathrm{pH}$ of biochar, when added to high soil $\mathrm{pH}$ in some instances, was recognized as the reason for the reduced plant growth (Van Zwieten et al., 2010; Haefele et al., 2011). The reasons for the reduced growth of cultivated plants in other cases are considerably less clear and can involve the direct phyto-toxicity of volatile fractions or the negative impacts of metals (Devonald, 1982). N immobilization after biochar addition appears to reduce $\mathrm{N}$ availability (Bruun et al., 2011), which could lead to decreased growth. A careful consideration of the characteristics related to each specific biochar is necessary. Furthermore, the effects of these characteristics could be insufficient for treating a particular soil type (Novak \& Busscher, 2013). The present study aimed to physically characterize biochar from three different feedstocks pyrolyzed under slow pyrolysis and gasification. The effects of biochar amendment on soil properties and plant growth were also analyzed. 


\section{Materials and Methods}

\subsection{Biochar Samples}

Three types of biochar were made from three types of regionally available feedstock in Malaysia by using two pyrolysis and one gasification methods. An empty fruit bunch (EFB) biochar sample was obtained from Nasmech Technologies Sdn Bhd (Malaysia). The wood biochar (WB) sample was produced by kilning mangrove wood logs, and the rice husk biochar (RHB) was supplied by Bernas Berhad (Malaysia).

Table 1. Summary of pyrolysis conditions for biochars

\begin{tabular}{lllll}
\hline Sample & Process & Temperature range & Atmosphere & Residence time \\
\hline EFB & Slow pyrolysis & $300-350{ }^{\circ} \mathrm{C}$ & Inert & $3 \mathrm{~h}$ \\
RHB & Gasification & $600-800{ }^{\circ} \mathrm{C}$ & Limited oxygen & seconds to minutes \\
WB & Slow pyrolysis charcoal kiln & $80-220{ }^{\circ} \mathrm{C}$ & Inert & days \\
\hline
\end{tabular}

\subsection{BET Surface Area and Scanning Electron Microscopy}

The BET surface area was measured by using a Thermo-Finnigan Sorptomatic Instrument (model 1990) on the basis of $\mathrm{N}_{2}$ adsorption at $-196{ }^{\circ} \mathrm{C}$. The biochar microstructures were investigated by using a JEOL JSM-6400 SEM. The samples were sliced into thin sections for an effective view of the cross-section. Images were obtained at $750 \times$ magnification.

\subsection{Biochar Effects on Soil Physical Properties}

The experimental plots at Farm No. 2 of the University of Putra Malaysia $\left(2^{\circ} 59^{\prime} 20.56^{\prime \prime} \mathrm{N}, 101^{\circ} 42^{\prime} 44.42^{\prime \prime} \mathrm{E}\right)$ were used for six months starting from April 2012. The biochar was incorporated to a compacted and low organic carbon loamy soil. A randomized block design was employed with the plots in quadruplicate and each measuring $1 \mathrm{~m} \times 1 \mathrm{~m}$, which involved a total of 28 plots ( 7 treatments with 4 replicates per treatment). The biochar application rates were 0,15 , and $30 \mathrm{t} / \mathrm{ha}^{-1}$. Biochar was uniformly applied to each plot by using rakes and was buried to a depth of $10 \mathrm{~cm}$ by using a disk harrow. The control plots $\left(0 \mathrm{t} / \mathrm{ha}^{-1}\right)$ were also disked.

\subsubsection{Determination of Soil Physical Properties}

A field study had been carried out to evaluate the effect of the biochar incorporation on soil physical properties (hydraulic conductivity, bulk density and porosity, drained upper limit, and permanent wilting point) .Saturated hydraulic conductivity was analyzed by using a constant head method. The core sampling technique $(5.1 \mathrm{~cm}$ height, $5 \mathrm{~cm}$ inner diameter) was used to measure bulk density. Total porosity was calculated from the dry bulk density and particle density.

$$
\text { Soil Porosity }=\left[1-\frac{\text { Bulk density }}{\text { particle density }}\right] \times 100
$$

The drained upper limit and permanent wilting point (PWP) were determined by using the pressure-membrane pressure-plate method at 33 and $1500 \mathrm{kpa}$, respectively.

\subsection{Biochar Effects on Plant Growth}

Loamy soil from Farm No. 2 of the University of Putra Malaysia was used as the potting medium. The characteristics of the soil are presented in Table 2. The soil was air-dried then $10 \mathrm{~kg}$ of it sieve to remove un-decomposed plant materials and use to fill thepots (height, $35 \mathrm{~cm}$; diameter, $20 \mathrm{~cm}$ ). The respective EFB, RHB, and WB treatments were applied at 0,15 , or $30 \mathrm{t} / \mathrm{ha}$, which equivalent to $0,52,105 \mathrm{~g} /$ pot respectively. For each treatment, 10 sweet corn seeds were originally sown per pot at $0.5 \mathrm{~cm}$ depth. The resulting seedlings were later thinned down to 5 plants per pot. Chemical fertilizers were applied at $50 \%$ of the recommended amount, that is, $120 \mathrm{~kg} / \mathrm{ha}$ for $\mathrm{N}, 60 \mathrm{~kg} / \mathrm{ha}$ for $\mathrm{P}_{2} \mathrm{O}_{5}$, and $95 \mathrm{~kg} / \mathrm{ha}$ for $\mathrm{K}_{2} \mathrm{O}$, i.e. using urea for $\mathrm{N}$, triple phosphate for $\mathrm{P}$, and muriate of potash for $\mathrm{K}$. The experiment was conducted in the shade house of the University of Putra Malaysia. A completely random design was used for the experiment with four replications. The plant height and shoot weights were recorded on five plants in each replication, plant height was measured using a steel ruler, fresh samples were put into the oven at $65^{\circ} \mathrm{C}$ for $48 \mathrm{~h}$ to get constant weight, and the dry weights of shoot were recorded. For period of 30 days during April 2013. 
Table 2. Chemicals properties of the soil used in the experiment

\begin{tabular}{cccccccccc}
\hline $\begin{array}{c}\text { Total C } \\
(\%)\end{array}$ & $\begin{array}{c}\text { Organic C } \\
\mathbf{( \% )}\end{array}$ & $\begin{array}{c}\text { Total } \mathbf{N} \\
\mathbf{( \% )}\end{array}$ & $\begin{array}{c}\text { Total H } \\
\mathbf{( \% )}\end{array}$ & $\begin{array}{c}\mathbf{S} \\
\mathbf{( \% )}\end{array}$ & $\begin{array}{c}\mathbf{C} / \mathbf{N} \\
\text { Ratio }\end{array}$ & $\begin{array}{c}\text { Total P } \\
(\mathbf{p p m})\end{array}$ & $\mathbf{p H}$ & $\begin{array}{c}\text { CEC } \\
(\mathbf{m e q} / \mathbf{1 0 0} \mathbf{g})\end{array}$ & Texture \\
\hline 1.32 & 0.99 & 0.12 & 0.23 & 0.13 & 11 & 369 & 4.4 & 3.75 & Loam \\
\hline
\end{tabular}

\subsection{Statistical Analysis}

One-way analysis of variance (ANOVA) was used to assess the biochar treatment effects on soil physical properties by using SPSS. The significant difference between the biochar treatments means were calculated via a Tukey post hoc test.

\section{Result and Discussion}

\subsection{Physical Characteristics of Biochar}

The Scanning electron microscopy images of WB (750×) clearly showed Smooth surface followed by EFB which image showed less rough then RHB which showed rough surface (Figure 1). These findings are consistent with those from the $\mathrm{N}_{2}$ surface area measurement, which suggested that micropores dominated the RHB surface.

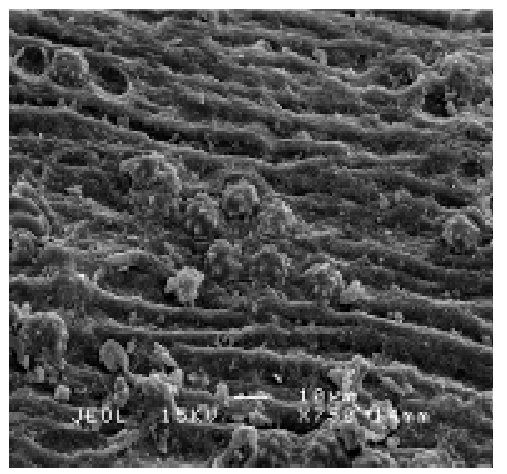

EFB

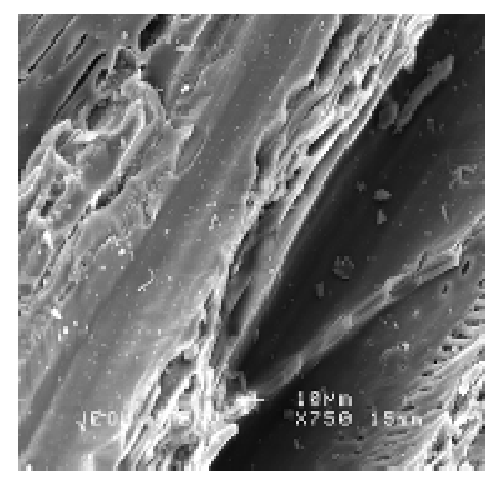

WB

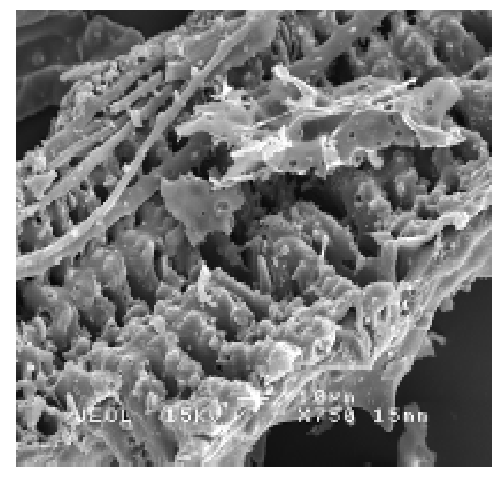

RHB

Figure 1. SEM images of RHB, WB, and EFB at $750 \times$ magnification

Table 3. Textural parameters from $\mathrm{N}_{2}$ adsorption isotherms of RHB, EFB, and WB

\begin{tabular}{ccccc}
\hline Sample & $\begin{array}{c}\mathbf{B E T}^{\mathbf{a}} \\
\left(\mathbf{m}^{2} / \mathbf{g}\right)\end{array}$ & $\begin{array}{c}\text { Micropore area } \\
\left(\mathbf{m}^{\mathbf{2}} / \mathbf{g}\right)\end{array}$ & $\begin{array}{c}\text { Micropore volume } \\
\left(\mathbf{c m}^{\mathbf{3}} \mathbf{g}\right)\end{array}$ & $\begin{array}{c}{\text { Average pore } \mathbf{w i d t h}^{\mathbf{d}}}^{\mathbf{b}} \\
(\mathbf{\AA})\end{array}$ \\
\hline $\mathrm{RHB}$ & 21.402 & 1.255 & 0.009 & 62.599 \\
$\mathrm{EFB}$ & 12.216 & 0.344 & 0.008 & 19.237 \\
WB & 4.112 & 0.257 & 0.002 & 48.210 \\
\hline
\end{tabular}

${ }^{\mathrm{a}}$ BET surface area.

${ }^{\mathrm{b}}$ Micropore surface area, calculated from the $t$-plot method.

${ }^{\mathrm{c}}$ Micropore pore volume, calculated from the $t$-plot method.

${ }^{\mathrm{d}}$ Average pore width, estimated from the BET and $\mathrm{Vt}$ whereby diameter average $=4 \mathrm{Vt} / \mathrm{BET}$.

Temperature is an important parameter that determines the surface area and the pore volume of the biochar. The surface area of RHB, which was produced by gasification at $600-800{ }^{\circ} \mathrm{C}$, was higher $\left(21.402 \mathrm{~m}^{2} / \mathrm{g}^{-1}\right)$ than those of EFB $\left(12.216 \mathrm{~m} \mathrm{~m}^{2} / \mathrm{g}^{-1}\right)$ and WB $\left(4.112 \mathrm{~m}^{2} / \mathrm{g}^{-1}\right)$, which were made via slow pyrolysis at $300-350{ }^{\circ} \mathrm{C}$ and $80-220^{\circ} \mathrm{C}$, respectively. Gasification creates more new pores in the material. The rapid de-volatilization creates highly porous materials, thereby increasing the BET surface area. The increase in surface area at higher temperatures can be attributed to the release of tars from the cross-linked framework (Angin et al., 2013). Consequently, the total pore volume was improved. The results suggested that the high temperature of gasification widened the daughter micropores by destroying the walls between adjacent pores. Thus, the 
development of pores was observed through the increased total pore volume (Table 3). A similar trend was also previously reported by Carrier et al. (2012), Ghani et al. (2013), and Mendez et al. (2013). The higher average diameter of the pores in the RHB indicated the greater proportion of wide pores.

\subsection{Effects of Biochar on Soil Physical Properties}

\subsubsection{Soil Bulk Density}

After approximately 200 day of incubation, a significant difference in the mean bulk density was observed in soils treated with biochar compared with the $\operatorname{control}\left(F_{(6,18)}=38.611, r^{2}=0.893, P<0.001\right)$ while Tukey HSD Post Poc test indicated that no significant difference had been shown between all of the EFB15, EFB30, RHB15, WB15, and WB30. The RHB30 treatment had the lowest mean bulk density, which was significantly decreased by $1.41-1.22 \mathrm{~cm} / \mathrm{h}$ when the average biochar concentration was $0-30 \mathrm{t} / \mathrm{h}$. The average diameter of the pores and micropore area in RHB were higher than those of EFB and WB (Table 3). This implies that a greater proportion of wide pores may have changed the soil structure by decreasing the soil bulk density. Previous studies have similarly reported that biochar amendment could decrease the soil bulk density (Laird et al., 2010; Devereux et al., 2012). Biochar application was previously reported to reduce the soil bulk density because of their extremely high porosity which leads to increasing the pore volume (Atkinson et al., 2010; Mukherjee \& Zimmerman, 2013). The various biochar characteristics significantly affected the properties of amended soil. The reduced soil bulk density after the addition of biochar shows that biochar has a lower bulk density than the non-amended soil (Atkinson et al., 2010). The reduced bulk density of agricultural soils is useful for crop production because it correlates to increased pore space (Schjønning et al., 2011).

\subsubsection{Hydraulic Conductivity}

Results showed significant differences in the hydraulic conductivity of soil when biochar treatment was applied compared with the non-amended soil (control) $\left(F_{(6,18)}=382.291, r^{2}=0.988, \mathrm{P}<0.001\right)$. Rice Husk Biochar, applied to the soil at rate $30 \mathrm{t} / \mathrm{ha}$ (RHB30) had the highest hydraulic conductivity, the average hydraulic conductivity increased from $0.99 \mathrm{~cm} / \mathrm{h}$ in the control to $2.41 \mathrm{~cm} / \mathrm{h}$ in RHB. Wood Biochar, applied to the soil at rate $15 \mathrm{t} / \mathrm{ha}$ (WB15) produced the lowest value among the treatments $(1.69 \mathrm{~cm} / \mathrm{h})$. No significant differences were observed between WB15 and WB30 (Figure 2A). Biochar application significantly decreased the soil bulk density because biochar has a smaller bulk density than soil (Verheijen et al., 2010), thereby leading to significantly higher hydraulic conductivity values (Ouyang et al., 2013).
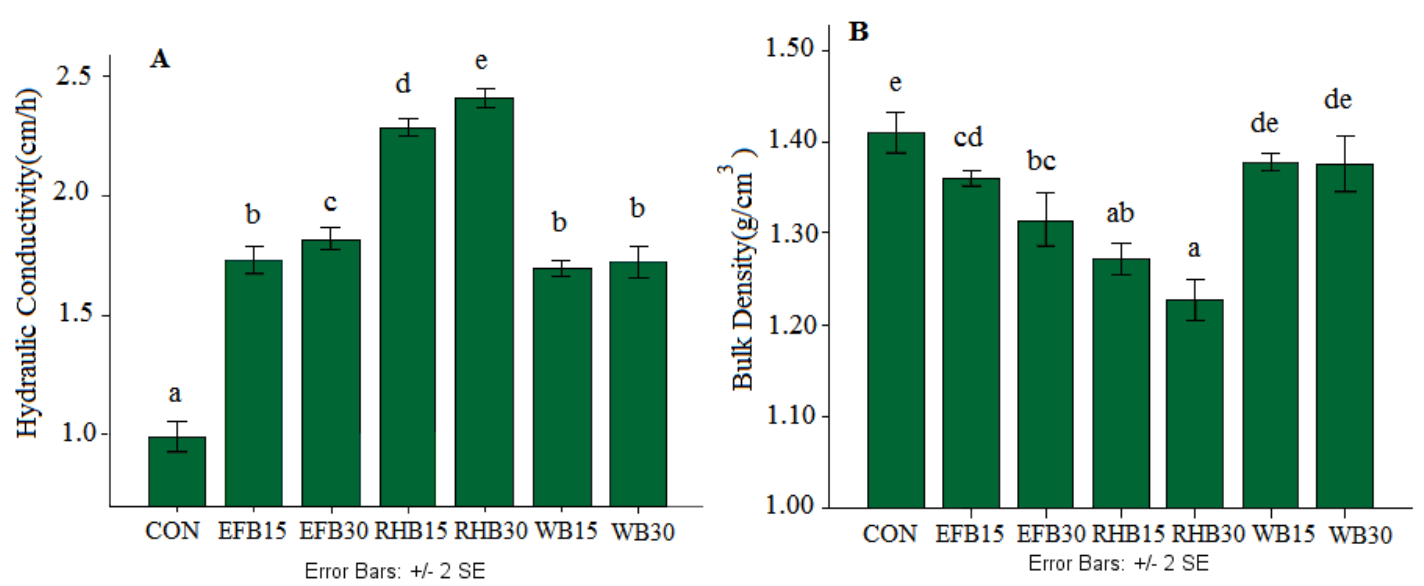

Figure 2. Effects of biochar treatments on (A) hydraulic conductivity and (B) soil bulk density. The error bars represent the mean $\pm 2 \mathrm{SE}, n=4$

Treatments represented by the same letter are significantly the same according to Tukey's HSD post-hoc test. CON: Control.

\subsubsection{Soil Porosity}

A significant difference in mean soil porosity was observed between soils treated with biochar and the non-amended soil. These results are the opposite of those of the average bulk density (Figure 2B), which showed an inverse relationship between these parameters. Maximum porosity was recorded in the RHB30 treatment with 
increased average soil porosity ranging from $46.79 \mathrm{~cm} / \mathrm{h}$ for WB15 to $53.68 \mathrm{~cm} / \mathrm{h}$ in RHB30 $\left(F_{(6,18)}=38.673, r^{2}\right.$ $=0.893, P<0.001)$. By contrast, no significant differences were observed when the other treatments were applied at an increasing rate (Figure 3).

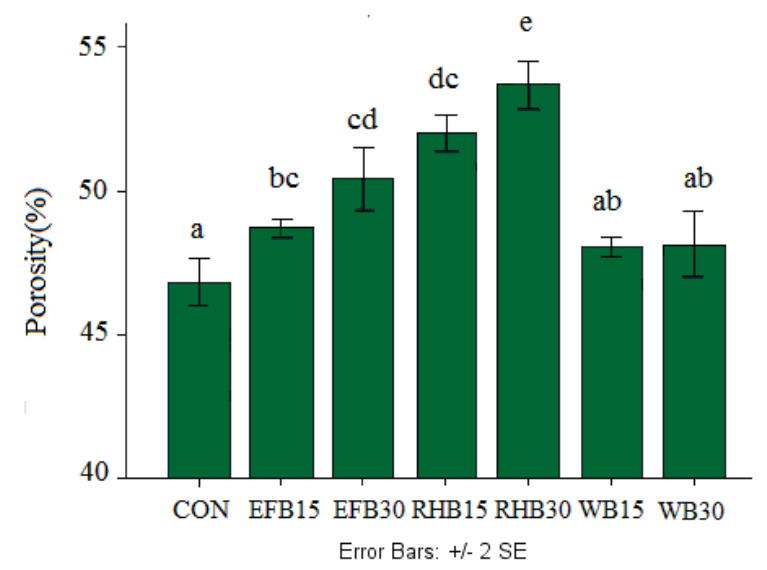

Figure 3. Effects of biochar treatment using different rates of EFB, WB, RHB, and the control (CON) for six months on soil porosity

The high surface area of RHB can improve the total micropore area and pore volume, thus consequently improving the total soil porosity. Asai et al. (2009) suggested that the use of biochar in rice-growing soils improved the pore-size distribution, thus consequently increasing soil porosity.

\subsubsection{Drained Upper Limit and Permanent Wilting Point}

The mean of the drained upper limit of the soil treated with different types of biochar significantly increased from $0.12 \%$ to $0.23 \%$ as compared with that of the control $\left(F_{(6,18)}=62.123 ; r^{2}=0.931\right)$. The RHB30 treatment recorded the highest mean of the drained upper limit $(0.23 \%)$ and the WB15 treatment, the lowest average drained upper limit of $0.14 \%$. No significant differences were observed between the control, EFB15, WB15, and WB30 treatments (Figure 4A). The various biochar characteristics significantly influenced the soil properties after biochar amendment. The drained upper limit of available water was increased after RHB amendment. No significant difference was observed between EFB and WB treatments. The effects of RHB treatment could be attributed to its high specific surface area (Shepherd et al., 2002). Thus, the potential for soil aeration was enhanced and the water content of the soil increased; these results were good indicators of soil quality.
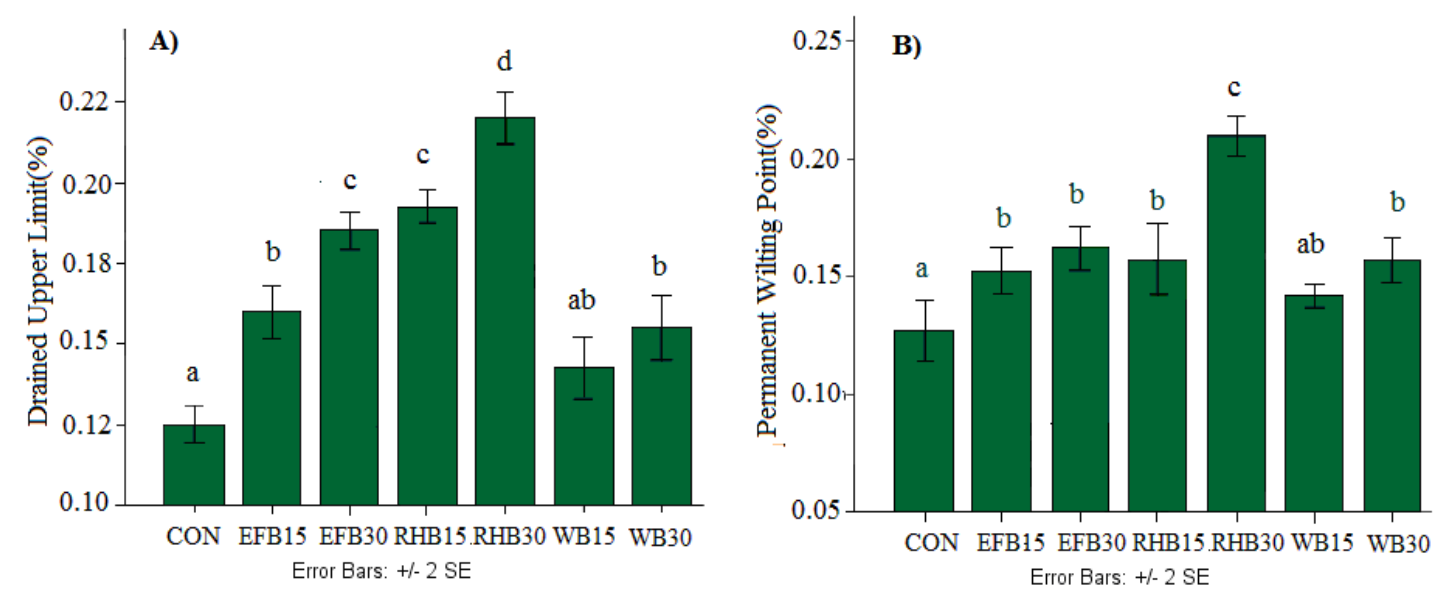

Figure 4. Effects of biochar treatment by using different rates of EFB, WB, RHB, and the control (CON) for six months on the (A) drained upper limit and (B) PWP. The error bars represent the mean \pm 2 SE $(n=4)$

Treatments represented by the same letter are significantly the same according to Tukey's HSD post-hoc test. 
The application of biochar influenced the amount of water retained in the soil at the PWP. Results indicated an increased water content at PWP over the control $\left(F_{(6,18)}=25.061, r^{2}=0.843, P<0.001\right)$ (Figure 4B). The maximum PWP was recorded at $0.21 \%$ for the RHB30 treatment, whereas the WB15 treatment had the lowest PWP at $0.14 \%$. No significant difference were observed when all other treatments were applied at an increasing rate The PWP of the amended soil with RHB30 was higher than those amended with EFB and WB. This difference may be associated with the increased microporosity and extensive pore structures of RHB, which were achieved by gasification at higher temperature (Shackley et al., 2012). Both properties of RHB (micropore area and pore width) were confirmed by BET analysis. In this study, the physical characteristics of biochar decreased the soil initial bulk density, thus leading to increase the soil water content. The improvement of biochar application on the drained upper limit and PWP were related to the high porosity of RHB compared with that of EFB and WB.

\subsection{Biochar Effects on Plant Growth}

Results showed a significant difference in the shoot dry weight of sweet corn grown on soils treated with the three types of biochar, compared with the non-amended soil $\left(F_{(6,21)}=247.48, P \geq 0.05\right)$. No statistically significant difference was found between the RHB15 and WB15 treatments, while EFB15 showed significant difference.
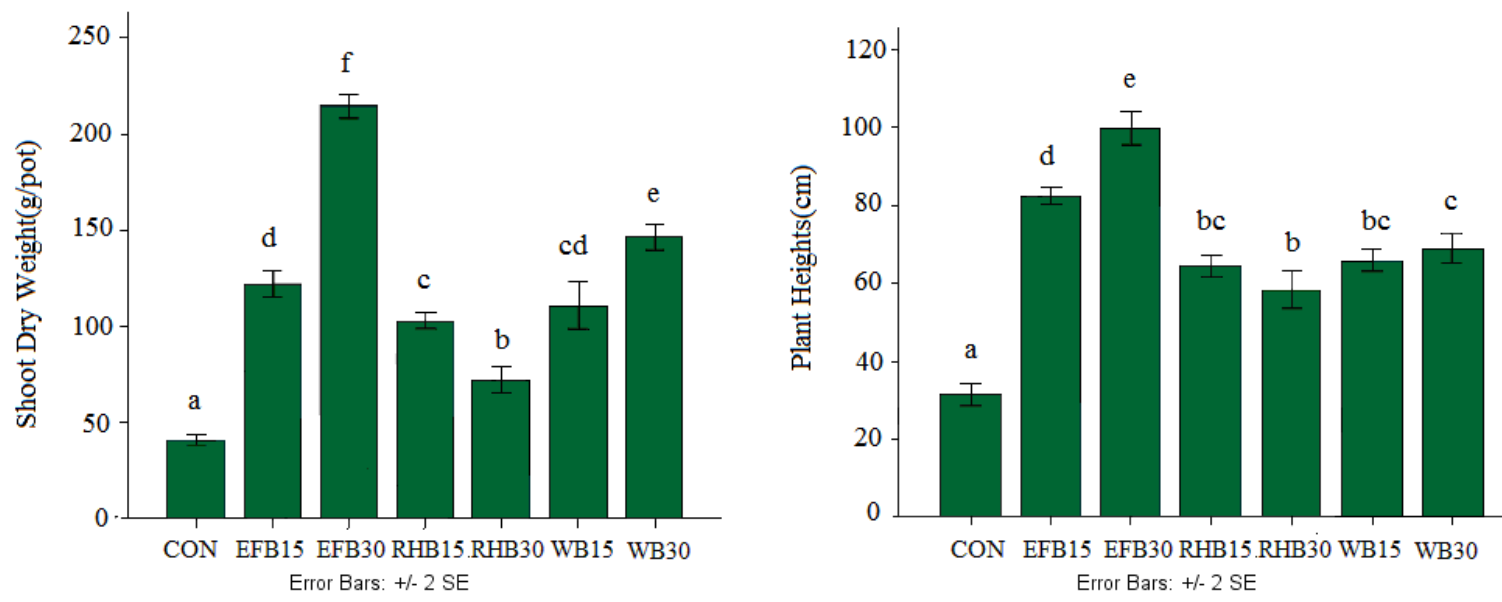

Figure 5. Sweet corn shoot dry weight by using soil amended with different rates of EFB, WB, RHB, and the control (CON) for 30 days. The error bars represent the mean $\pm 2 \mathrm{SE}(n=4)$

Treatments represented by the same letter are not significantly different according to Tukey's HSD post-hoc test.

The treatments could be ranked on the basis of the growth of the planted sweet corn: RHB30 $<$ RHB15 $<$ WB15 $<$ EFB15 < WB30 < EFB30. The EFB30 treatment had the maximum average growth (220 g per pot; Figure 5). Several factors led to improved growth of sweet corn, and they may have acted individually or simultaneously. The increase in $\mathrm{pH}$ and decreased the $\mathrm{Al}$ and $\mathrm{Fe}$ contents of the soil are considered important factors for plant growth improvement (Masulili et al., 2010). By contrast, RHB30 showed the least average growth (75 g per pot) compared with plants from the control. The unconverted cellulosic and hemicellulosic fractions in RHB are noticeably proportional with the short-term biochar degradation in soil. Given that these labile carbohydrates are quickly mineralized, a high $\mathrm{C} / \mathrm{N}$ ratio might cause the microbial immobilization of soil $\mathrm{N}$. The abovementioned results were in agreement with those of Bruun et al. (2011) from their work on the nfluence of fast pyrolysis temperature on biochar labile fraction and short-term carbon loss in a loamy soil.

\section{Conclusions}

Applying biochar substances by using local materials is assessing promises of being an environmentally sound in enhancing the physical characteristics of soil and crop productivity in Malaysia. Biochar incorporation into soil has impact on soil water content and hydraulic conductivity, leads to improve soil structure, and improved moisture characteristics, that related to the extensive pore structures, surface characteristics, and high porosity of RHB as compared to EFB and WB, whilst EFB applied at rates $30 \mathrm{t} /$ ha has important potential benefits for sweet corn growth. 


\section{References}

Ahmad, M., Rajapaksha, A. U., Lim, J. E., Zhang, M., Bolan, N., Mohan, D., \& Ok, Y. S. (2014). Biochar as a sorbent for contaminant management in soil and water: A review. Chemosphere, 99, 19-33. http://dx.doi.org/10.1016/j.chemosphere.2013.10.071

Angin, D., Altintig, E., \& Kose, T. E. (2013). Influence of process parameters on the surface and chemical properties of activated carbon obtained from biochar by chemical activation. Bioresource Technology, 148, 542-549. http://dx.doi.org/10.1016/j.biortech.2013.08.164

Asai, H., Samson, B. K., Stephan, H. M., Songyikhangsuthor, K., Homma, K., Kiyono, Y., \& Horie, T. (2009). Biochar amendment techniques for upland rice production in Northern Laos 1. Soil physical properties, leaf SPAD and grain yield. Field Crops Research, 111(1-2), 81-84. http://dx.doi.org/10.1016/j.fcr.2008.10.008

Atkinson, C. J., Fitzgerald, J. D., \& Hipps, N. A. (2010). Potential mechanisms for achieving agricultural benefits from biochar application to temperate soils: A review. Plant and Soil, 337(1-2), 1-18. http://dx.doi.org/10.1007/s11104-010-0464-5

Belyaeva, O. N., \& Haynes, R. J. (2012). Comparison of the effects of conventional organic amendments and biochar on the chemical, physical and microbial properties of coal fly ash as a plant growth medium. Environmental Earth Sciences, 66(7), 1987-1997. http://dx.doi.org/10.1007/s12665-011-1424-y

Brewer, C. E., Hu, Y. Y., Schmidt-Rohr, K., Loynachan, T. E., Laird, D. A., \& Brown, R. C. (2012). Extent of Pyrolysis Impacts on Fast Pyrolysis Biochar Properties. Journal of Environmental Quality, 41(4), 1115-1122. http://dx.doi.org/10.2134/Jeq2011.0118

Bruun, E. W., Hauggaard-Nielsen, H., Ibrahim, N., Egsgaard, H., Ambus, P., Jensen, P. A., \& Dam-Johansen, K. (2011). Influence of fast pyrolysis temperature on biochar labile fraction and short-term carbon loss in a loamy soil. Biomass \& Bioenergy, 35(3), 1182-1189. http://dx.doi.org/10.1016/j.biombioe.2010.12.008

Carrier, M., Hardie, A. G., Uras, U., Gorgens, J., \& Knoetze, J. (2012). Production of char from vacuum pyrolysis of South-African sugar cane bagasse and its characterization as activated carbon and biochar. Journal of Analytical and Applied Pyrolysis, 96, 24-32. http://dx.doi.org/10.1016/j.jaap.2012.02.016

Chan, K. Y., Van Zwieten, L., Meszaros, I., Downie, A., \& Joseph, S. (2007). Agronomic values of greenwaste biochar as a soil amendment. Australian Journal of Soil Research, 45(8), 629-634. http://dx.doi.org/10.1071/Sr07109

Chen, Y., Shinogi, Y., \& Taira, M. (2010). Influence of biochar use on sugarcane growth, soil parameters, and groundwater quality. Australian Journal of Soil Research, 48(6-7), 526-530. http://dx.doi.org/10.1071/Sr10011

Devereux, R. C., Sturrock, C. J., \& Mooney, S. J. (2012). The effects of biochar on soil physical properties and winter wheat growth. Earth and Environmental Science Transactions of the Royal Society of Edinburgh, 103(1), 13-18. http://dx.doi.org/10.1017/S1755691012000011

Devonald, V. (1982). The effect of wood charcoal on the growth and nodulation of garden peas in pot culture. Plant and Soil, 66(1), 125-127. http://dx.doi.org/10.1007/BF02203411

Gajic, A., \& Koch, H. J. (2012). Sugar beet (L.) growth reduction caused by hydrochar is related to nitrogen supply. Journal of Environmental Quality, 41(4), 1067-1075. http://dx.doi.org/10.2134/jeq2011.0237

Gaskin, J. W., Speir, R. A., Harris, K., Das, K. C., Lee, R. D., Morris, L. A., \& Fisher, D. S. (2010). Effect of Peanut Hull and Pine Chip Biochar on Soil Nutrients, Corn Nutrient Status, and Yield. Agronomy Journal, 102(2), 623-633. http://dx.doi.org/10.2134/agronj2009.0083

Ghani, W. A. K., Mohd, A., da Silva, G., Bachmann, R. T., Taufiq-Yap, Y. H., Rashid, U., \& Al-Muhtaseb, A. H. (2013). Biochar production from waste rubber-wood-sawdust and its potential use in C sequestration: Chemical and physical characterization. Industrial Crops and Products, 44, 18-24. http://dx.doi.org/10.1016/j.indcrop.2012.10.017

Glaser, B., Lehmann, J., \& Zech, W. (2002). Ameliorating physical and chemical properties of highly weathered soils in the tropics with charcoal - A review. Biology and Fertility of Soils, 35(4), 219-230. http://dx.doi.org/10.1007/s00374-002-0466-4

Guerena, D., Lehmann, J., Hanley, K., Enders, A., Hyland, C., \& Riha, S. (2013). Nitrogen dynamics following field application of biochar in a temperate North American maize-based production system. Plant and Soil, 365(1-2), 239-254. http://dx.doi.org/10.1007/s11104-012-1383-4 
Haefele, S. M., Konboon, Y., Wongboon, W., Amarante, S., Maarifat, A. A., Pfeiffer, E. M., \& Knoblauch, C. (2011). Effects and fate of biochar from rice residues in rice-based systems. Field Crops Research, 121(3), 430-440. http://dx.doi.org/10.1016/j.fcr.2011.01.014

Jaiswal, A. K., Elad, Y., Graber, E. R., \& Frenkel, O. (2014). Rhizoctonia solani suppression and plant growth promotion in cucumber as affected by biochar pyrolysis temperature, feedstock and concentration. Soil Biology \& Biochemistry, 69, 110-118. http://dx.doi.org/10.1016/j.soilbio.2013.10.051

Kameyama, K., Miyamoto, T., Shiono, T., \& Shinogi, Y. (2012). Influence of Sugarcane Bagasse-derived Biochar Application on Nitrate Leaching in Calcaric Dark Red Soil. Journal of Environmental Quality, 41(4), 1131-1137. http://dx.doi.org/10.2134/Jeq2010.0453

Kloss, S., Zehetner, F., Wimmer, B., Buecker, J., Rempt, F., \& Soja, G. (2014). Biochar application to temperate soils: Effects on soil fertility and crop growth under greenhouse conditions. Journal of Plant Nutrition and Soil Science, 177(1), 3-15. http://dx.doi.org/10.1002/jpln.201200282

Laird, D. A., Fleming, P., Davis, D. D., Horton, R., Wang, B. Q., \& Karlen, D. L. (2010). Impact of biochar amendments on the quality of a typical Midwestern agricultural soil. Geoderma, 158(3-4), 443-449. http://dx.doi.org/10.1016/j.geoderma.2010.05.013

Major, J., Lehmann, J., Rondon, M., \& Goodale, C. (2010). Fate of soil-applied black carbon: Downward migration, leaching and soil respiration. Global Change Biology, 16(4), 1366-1379. http://dx.doi.org/10.1111/j.1365-2486.2009.02044.x

Masto, R. E., Ansari, M. A., George, J., Selvi, V. A., \& Ram, L. C. (2013). Co-application of biochar and lignite fly ash on soil nutrients and biological parameters at different crop growth stages of Zea mays. Ecological Engineering, 58, 314-322. http://dx.doi.org/10.1016/j.ecoleng.2013.07.011

Masulili, A., Utomo, W. H., \& Syechfani, M. (2010). Rice husk biochar for rice based cropping system in acid soil 1. The characteristics of rice husk biochar and its influence on the properties of acid sulfate soils and rice growth in West Kalimantan, Indonesia. Journal of Agricultural Science, 2(1), 39.

Mendez, A., Terradillos, M., \& Gasco, G. (2013). Physicochemical and agronomic properties of biochar from sewage sludge pyrolysed at different temperatures. Journal of Analytical and Applied Pyrolysis, 102, 124-130. http://dx.doi.org/10.1016/j.jaap.2013.03.006

Novak, J. M., \& Busscher, W. J. (2013). Selection and Use of Designer Biochars to Improve Characteristics of Southeastern USA Coastal Plain Degraded Soils. In J. W. Lee (Ed.), Advanced Biofuels and Bioproducts (pp. 69-96). New York: Springer. http://dx.doi.org/10.1007/978-1-4614-3348-4_7

Ouyang, L., Wang, F., Tang, J., Yu, L., \& Zhang, R. (2013). Effects of biochar amendment on soil aggregates and hydraulic properties. Journal of soil science and plant nutrition, 13(4), 991-1002.

Schjønning, P., Thomsen, I. K., Petersen, S. O., Kristensen, K., \& Christensen, B. T. (2011). Relating soil microbial activity to water content and tillage-induced differences in soil structure. Geoderma, 163(3), 256-264. http://dx.doi.org/10.1016/j.geoderma.2011.04.022

Shackley, S., Carter, S., Knowles, T., Middelink, E., Haefele, S., Sohi, S., \& Haszeldine, S. (2012). Sustainable gasification-biochar systems? A case-study of rice-husk gasification in Cambodia, Part I: Context, chemical properties, environmental and health and safety issues. Energy Policy, 42, 49-58. http://dx.doi.org/10.1016/j.enpol.2011.11.026

Shepherd, M., Harrison, R., \& Webb, J. (2002). Managing soil organic matter-implications for soil structure on organic farms. Soil Use and Management, 18(S1), 284-292. http://dx.doi.org/10.1079/SUM2002134

Streubel, J. D., Collins, H. P., Garcia-Perez, M., Tarara, J., Granatstein, D., \& Kruger, C. E. (2011). Influence of Contrasting Biochar Types on Five Soils at Increasing Rates of Application. Soil Science Society of America Journal, 75(4), 1402-1413. http://dx.doi.org/10.2136/sssaj2010.0325

Tian, Y., Sun, X. Y., Li, S. Y., Wang, H. Y., Wang, L. Z., Cao, J. X., \& Zhang, L. (2012). Biochar made from green waste as peat substitute in growth media for Calathea rotundifola cv. Fasciata. Scientia Horticulturae, 143, 15-18. http://dx.doi.org/10.1016/j.scienta.2012.05.018

Van Zwieten, L., Kimber, S., Morris, S., Chan, K., Downie, A., Rust, J., ... Cowie, A. (2010). Effects of biochar from slow pyrolysis of papermill waste on agronomic performance and soil fertility. Plant and Soil, 327(1-2), 235-246. http://dx.doi.org/10.1007/s11104-009-0050-x 
Ventura, F., Salvatorelli, F., Piana, S., Pieri, L., \& Pisa, P. R. (2012). The effects of biochar on the physical properties of bare soil. Earth and Environmental Science Transactions of the Royal Society of Edinburgh, 103(1), 5-11. http://dx.doi.org/10.1017/S1755691012000059

Verheijen, F., Jeffery, S., Bastos, A., Van der Velde, M., \& Diafas, I. (2010). Biochar application to soils. Institute for Environment and Sustainability, Luxembourg.

\section{Copyrights}

Copyright for this article is retained by the author(s), with first publication rights granted to the journal.

This is an open-access article distributed under the terms and conditions of the Creative Commons Attribution license (http://creativecommons.org/licenses/by/3.0/). 